\title{
FIELD TESTS, MODEL VALIDATION AND PERFORMANCE OF A CO COMMERCIAL REFRIGERATION PLANT INTEGRATED WITH HVAC SYSTEM
}

\author{
P. D’Agaro* , M.A. Coppola, G. Cortella \\ Polytechnic Department of Engineering and Architecture, University of Udine \\ via delle Scienze 206, 33100 Udine, Italy \\ *Corresponding author, paola.dagaro@uniud.it
}

\begin{abstract}
A fully instrumented $\mathrm{CO}_{2}$ trans-critical booster system with parallel compression, in operation in a small size supermarket in northern Italy, made available measured data that allowed monitoring its performance.

The entire refrigeration system of the supermarket, i.e. the Commercial Refrigerating Unit, the refrigerated display cabinets and cold rooms, have been modelled in TRNSYS with in-house types for all components. The comparison with the field data available from monitoring the plant allowed to thoroughly calibrate the model, spanning the operation conditions of a whole year. The validated model is a reliable and powerful tool, usable to predict the plant performance in several conditions and to evaluate the feasibility and effectiveness of the integration with DHW/HVAC systems. Measurements and simulations show that, at mild climate conditions, it is possible and effective to fully provide HVAC and refrigeration duties with a single all-in-one unit properly designed and operated.
\end{abstract}

\section{KEYWORDS:}

$\mathrm{CO}_{2}$ booster system, Field measurements, Commercial refrigeration, Modelling, Heat recovery, HVAC integration

\section{NOMENCLATURE}

$\begin{array}{llll}\text { AC } & \text { Air Conditioning } & \text { HVAC } & \text { Heating, Ventilation, Air Conditioning } \\ \text { COP } & \text { Coefficient Of Performance } & \text { INT } & \text { Intermediate } \\ \text { CRU } & \text { Commercial Refrigeration Unit } & \text { LS } & \text { Low Stage } \\ \text { DHW } & \text { Domestic Hot Water } & \text { LT } & \text { Low Temperature } \\ \text { HDD } & \left.\text { Heating Degree Days (base } t: 20^{\circ} \mathrm{C}\right) & \text { MT } & \text { Medium Temperature } \\ \text { HFC } & \text { HydroFluoroCarbon } & p & \text { Pressure [bar] } \\ \text { GWP } & \text { Global Warming Potential } & q_{\text {heating }} & \text { Heating demand }[W] \\ \text { HPV } & \text { High Pressure Valve } & q_{M T+L T} & \text { Total cooling capacity }[W] \\ \text { HR } & \text { Heat Recovery } & \text { RDC } & \text { Refrigerated Display Cabinets } \\ \text { HR1 } & \text { Heat Exchanger for DHW heating } & t & \text { Temperature }\left[{ }^{\circ} \mathrm{C}\right]\end{array}$




\section{INTRODUCTION}

$\mathrm{CO}_{2}$ is a candidate refrigerant in commercial refrigeration, with the aim of removing any direct greenhouse effect. Unfortunately, in warm and hot climates the energy efficiency of $\mathrm{CO}_{2}$ plant suffers operation at transcritical conditions, partly invalidating the efforts to reduce the global warming effect. On the other hand, transcritical operation and the related high discharge temperature at the compressors allow great opportunities for heat recovery (Polzot, 2017a; Karampour and Sawalha, 2014a).

Among several others, Sawalha (2013) evaluated that heat recovery from a $\mathrm{CO}_{2}$ system can cover a significant fraction or the entire heating demand of an average size supermarket depending on the climate, with $8 \%$ energy saving compared against a conventional R404A system where a separate heat pump is used for the heating needs. Karampour and Sawalha (2014b) found that a booster system in heat recovery mode and commercially available heat pumps have comparable values of the seasonal performance factor.

D’Agaro et al (2018) compared a $\mathrm{CO}_{2}$ system with parallel compression and heat recovery for full heating and DHW purposes to a R404A direct expansion system and to a R134a/R744 cascade with separate heat pumps for heating and DHW. With the components considered and the control rules adopted, they found up to 6-7.7\% energy saving at warm climate (751 HDD) and up to 16\% at mild climate (2404 HDD) by using the heat recovery system.

Heat recovery definitely affects the performance of the refrigeration system, and control rules play an essential role (Ge and Tassou, 2014). Two major control strategies can be followed (Reinholdt and Madsen, 2010), aiming at the maximization of the COP of the refrigerating unit, allowing heat recovery only when it is freely available, or at the maximization of the amount of heat recovered, by imposing particular operating conditions to the refrigerating plant especially with regard to the condensing/gas cooling pressure. One strong constrain comes from the need to match the heat demand with its availability, which can force heat recovery in adverse operating conditions for the refrigerating plant. Some mitigation of its negative effect on the energy consumption can be attained by using a heat storage to uncouple demand and availability and allow the best exploitation of recovery. Polzot et al (2016a, 2016b) investigated the effect of a $950 \mathrm{~m}^{3}$ water reservoir as heat storage for heat recovery, finding that with a proper temperature control it can effectively act as a sink for heat pumps and allow up to $9 \%$ energy savings. Nöding et al (2016), have investigated how to adapt the operation strategy of a transcritical $\mathrm{CO}_{2}$ system with heat storages to minimize the overall energy consumption with both heating and cooling recovery. In fact, in the view of a full integration of the HVAC and refrigerating systems, cold water from the AC plant can be potentially used to perform subcooling at the gas cooler exit, thus improving the $\mathrm{COP}$ of the refrigerating unit. The positive effect of subcooling at high outdoor temperature has been widely demonstrated (Llopis et al, 2018), both theoretically (Hafner et al, 2014, Llopis et al. 2015, Gullo et al. 2016) and experimentally (Llopis et al. 2016) but the profitability of the integrated system when 
subcooling is performed by the AC chiller is still an open issue. On the other hand, in the view of reducing substantially the investment costs and increasing the compactness of the systems, the air conditioning function can be assigned to the refrigerating unit. Various configurations can be implemented, where the evaporator for AC is generally at the liquid receiver pressure (Karampour and Sawalha, 2016a, 2016b, 2017, 2018; Gullo et al, 2017, Polzot et al 2016b, Pardiñas et al, 2018). It has been found that most systems have similar or even slightly lower annual energy consumption compared with conventional HFC refrigeration and AC systems. It appears clearly that a lot of options are available to minimize the impact of investment and running costs (or energy consumption) when carbon dioxide is considered. For the best exploitation of all these options, a thorough evaluation of the energy consumption is required, which can be performed by modelling the whole system (Karampour and Sawalha 2014a, Polzot 2017a, D’Agaro et al. 2018) necessarily in transient conditions if storage devices and heating/cooling demand of the building are involved. A thorough validation of the model is advisable, through comparison with laboratory or field data. While laboratory prototype plants have the advantage of a tight control of the operation and allow to optimize the design and control rules of single components, (Hafner and Banasiak 2016a, Llopis et al. 2016), the comparison with field data allows to authenticate the results of the models at actual operating conditions, in the presence of external perturbations, thus allowing a deeper knowledge of the system and a fairer estimation of the energy consumption at different actual conditions (Minetto et al. 2014, Hafner et al. 2016b, Karampour and Sawalha 2017, Cortella et al. 2018). In this paper, measurements taken on a $\mathrm{CO}_{2}$ transcritical plant in a small size supermarket in Italy are considered, at mild climate characterized by an annual average temperature $15.1^{\circ} \mathrm{C}$ and $2132 \mathrm{HDD}$. The system is designed to supply refrigeration for the cold rooms and display cabinets and is integrated with the HVAC plant to perform heating through heat recovery, and supply air conditioning. The field data allow the validation of a comprehensive model built in the Trnsys environment (Klein et al. 2010), where each component, from the display cabinets to the whole refrigerating plant, heat pumps and heat storages, is described by in-house routines. Time dependent simulations are performed, with a 1 min time step based on actual weather and room climate conditions, for the validation of the model on a weekly basis. Then annual simulations with 15 minutes time step are performed for the estimation of power profiles and annual energy consumption, in order to check the feasibility and convenience of heat recovery and AC integration, and optimize the control strategies.

\section{REFRIGERATION SYSTEM}

The Commercial Refrigeration Unit (CRU) studied and analyzed in detail in this work is an existing monitored Transcritical $\mathrm{CO}_{2}$ Booster system with parallel compression installed in a supermarket which has been refurbished in the framework of the FP7 European Project CommONEnergy (Cortella 2014, Commonenergy 2017). It is a small supermarket with a selling area of approximately $1200 \mathrm{~m}^{2}$, located in Modena (IT), that has undergone renovation during summer 2016, where the retrofitting process involved several aspects such as plants, envelope, solutions for both artificial and natural lighting and the refrigeration system. 


\subsection{New Refrigeration System}

The previous refrigeration system has been replaced with a new generation type, which is composed by a transcritical $\mathrm{CO}_{2}$ booster system, namely the new CRU, and closed refrigerated display cabinets (RDC), both for chilled and frozen food.

The installation involved approximately $14 \mathrm{~m}$ of new refrigerated display cabinets for the low temperature level (LT) and $40 \mathrm{~m}$ of closed cabinets and $23 \mathrm{~m}$ of serve-over or open ones for the medium temperature level (MT). The nominal compressor capacity is of $70.5 \mathrm{~kW}$ and $10.8 \mathrm{~kW}$ respectively for the MT and LT application.

The system works at two temperature levels, LT and MT (Figure 1), the design values are fixed at $-35^{\circ} \mathrm{C}$ for frozen food equipment and $-10{ }^{\circ} \mathrm{C}$ for chilled food. Each stage is equipped with its own set of compressors: the Low Stage (LS) works between the LT level and the MT one, while the High Stage (HS) works between the MT level and the high stage pressure $p_{H S}$ driven by the outdoor and operating conditions. In addition, there is a third compressor stage, the parallel compressor, that is used to process the flash gas coming from the liquid receiver placed after the first expansion valve HPV (High Pressure Valve) at an intermediate pressure $p_{I N T}$ of 35.0 bar, to the high stage pressure $p_{H S}$.

Both compressor racks, LS and HS, are composed by two compressors, distinguished as master and slave compressor. The master is controlled by an inverter and the slave is an ON/OFF type. The high stage nominal electrical power is of $23.7 \mathrm{~kW}, 8.1 \mathrm{~kW}$ for the master compressor (displacement of $9.2 \mathrm{~m}^{3} \mathrm{~h}^{-1}$ at $1450 \mathrm{rpm}$ ) and $15.6 \mathrm{~kW}$ for the slave (displacement of $17.8 \mathrm{~m}^{3} \mathrm{~h}^{-1}$ at $1450 \mathrm{rpm}$ ); similarly, the low stage has a nominal electrical power of $2.4 \mathrm{~kW}, 1.05 \mathrm{~kW}$ for the master (displacement of $2.71 \mathrm{~m}^{3} \mathrm{~h}^{-1}$ at $1450 \mathrm{rpm}$ ) and $1.35 \mathrm{~kW}$ for the slave (displacement of $3.48 \mathrm{~m}^{3} \mathrm{~h}^{-1}$ at $1450 \mathrm{rpm}$ ). Other $9 \mathrm{~kW}$ of nominal electrical power must be considered for parallel compression.

The system is designed to be integrated with DHW/HVAC systems as shown in Figure 1. The heat recovery at two temperature levels, for DHW production and for space heating, is allowed through heat exchangers HR1 and HR2 respectively.

The CRU can provide cooling capacity for air conditioning, by means of a heat exchanger (AC) that works with refrigerant at the intermediate pressure level, where the temperature is suitable for chilled water production.

The system is instrumented with sensors placed as in Fig. 1, to measure temperature (Pt500, $\pm 0.5 \mathrm{~K}$ ), pressure (pressure gauges 0-80 bar for the evaporating pressure, 0-140 bar for the high stage and intermediate pressure, $\pm 1 \%$ f. s.), refrigerant mass flow rate (Coriolis mass flow meter, $\pm 0.1 \%$ reading), heat meters for the secondary fluids at the heat exchangers (ultrasonic mass flow meter, Pt500 temperature sensors, $\pm 0.8 \%$ ), electrical power (energy analyser, $\pm 1 \%$ ). 


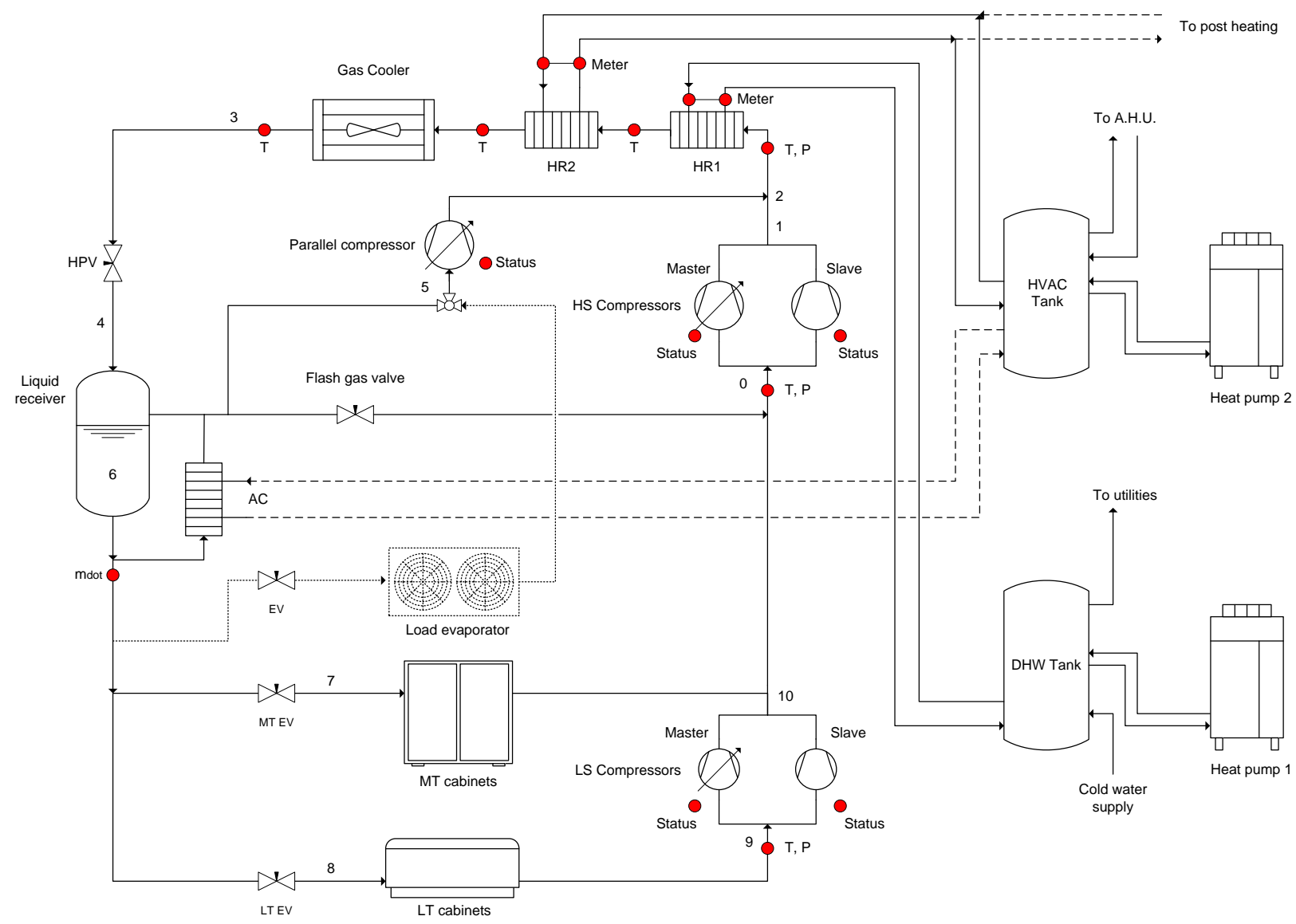

Figure 1: Schematic drawing of the $\mathrm{CO}_{2}$ refrigeration system with heat recovery equipment. The approximate position of the probes is indicated by the red flags. $T=$ temperature probe, $P=$ pressure gauge, Meter=energy meter, $m_{d o t}=m a s s$ flow meter, Status=compressor status sensor.

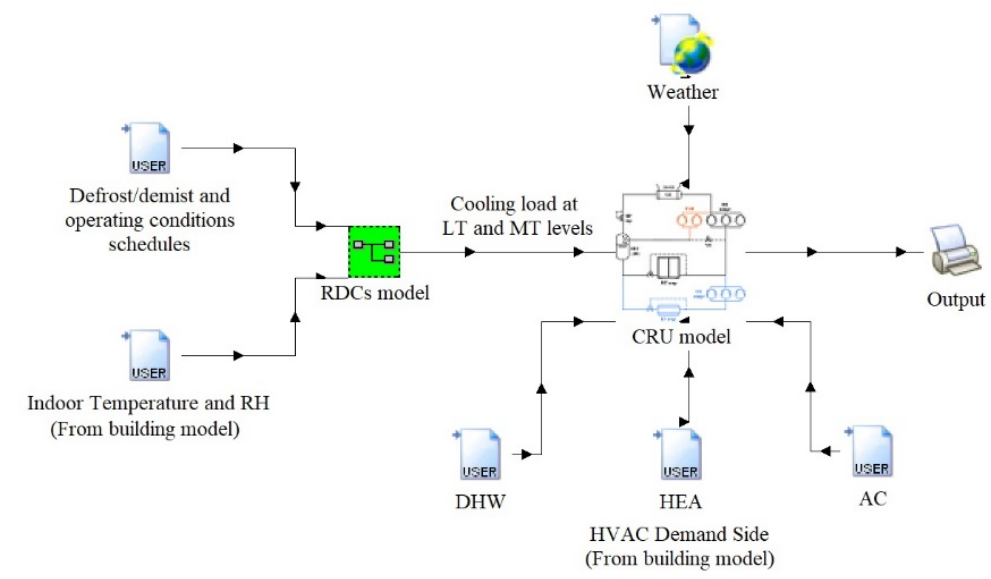

Figure 2: Schematic drawing of the Refrigeration System Model

\subsection{Thermodynamic model of the CRU and control rules}

The mathematical models of the components of the refrigeration system, such as display cabinets, cold rooms and commercial refrigeration units, have been developed in the TRNSYS environment, as it allows carrying out dynamic simulations of a complex system, which is sketched in Figure 2. For the evaluation of thermal loads on the HVAC system (HVAC Demand Side) and of mutual interactions between cabinets and indoor 
environment (Indoor Temperature and RH), the model has been extended to the whole building in its climate conditions.

The model of the display cabinets and of the cold rooms (RDC model), which is described in detail in Polzot et al. (2017a), estimates the total cooling load on the evaporators of the commercial refrigeration unit by tuning the performance at rated conditions according to the realistic and time-dependent working conditions in a supermarket. At the same time, the sensible and latent heat from the refrigerated equipment to the HVAC system are calculated via the evaluation of the heat and mass transfer between the refrigerated volume and the surroundings.

The simulations of the $\mathrm{CO}_{2}$ transcritical booster system with parallel compression are based on sub-hourly profiles of the cooling load at the evaporators, of the outdoor temperature and of the heating demands. A detailed description of a general booster system can be found in Polzot et al. (2016a). The thermodynamic and thermophysical properties of the refrigerants are calculated by linking our in-house routines in the TRNSYS environment to the CoolProp libraries (Bell et al., 2014).

The functioning of the compressors has been modelled through the compressor correlations provided by the manufacturer on experimental data (Bitzer, 2017) in accordance with the standard EN12900:2013 (EN12900:2013). Given the operating conditions of the compressors, such as suction and discharge pressures and the superheating degree, it is possible to calculate with good accuracy the power utilization, the refrigerant flow rate and outlet temperature at each stage, as well as establishing the status of the inverter and of the slave compressor at every time step once the cooling load, and thus the refrigerant flow rate required, is known. The correlations for the compressor discharge temperature are built by fitting the results obtained with the BITZER Software. As an example, the correlations of the power and discharge temperature for the HS compressors are depicted in Figure 3.

The correct application of the control rules in the plant has been verified with the available monitoring data. They are implemented in the model as follows:

- if there is no heating demand from the HVAC system in the supermarket ( $\left.q_{\text {heating }}=0\right)$, the high stage pressure $p_{H S}$ is driven by the outdoor temperature as in Polzot 2017a. In subcritical mode, the condensing temperature is set depending on the outdoor air temperature, considering an appropriate approach temperature and a minimum condensing level (see Table 1). In particular, in transcritical and transitional operation $\left(t_{e x t}>20^{\circ} \mathrm{C}\right)$ the parallel compressor is activated and the high stage pressure $p_{H S}$ is set according to the following correlation

$$
p_{H S}=\max \left(75 ; 1.75 t_{G C_{-} \text {out }}+22.13\right)[\mathrm{bar}]
$$

where $t_{G C_{-} \text {out }}\left[{ }^{\circ} \mathrm{C}\right]$ is the temperature at the exit of the condenser/gas cooler, while the parallel compressor suction pressure $p_{I N T}$ is keep constant (Table 1 ).

The transition from subcritical to transcritical operation is actually performed by means of an electronic controller which conveniently operates the back pressure valve at the inlet of the liquid receiver. A smooth change of gas cooler pressure is obtained from the subcritical operation mode (condensing pressure related to condensing temperature) to the transcritical one. 
- when the HVAC system in the supermarket requires heating power ( $q_{\text {heating }}>0$ ), the refrigerating unit is switched to transcritical mode in order to raise the HS discharge temperature and insure to provide space heating. The discharge pressure $p_{H S}$ is increased to 78 bar and heat recovery in the HR2 heat exchanger is activated in series to the HR1. In winter season, the parallel compressor is turned off because the temperature at the exit of the gas cooler keeps a low production of flash gas.

The LS and HS compressors are set to operate in order to process the required flow rate, the amount required to cope with the cooling demand at the two evaporating temperature levels at each instant.

As already mentioned, each stage is composed of two compressors, one controlled by an inverter and the other one not. The operation range of the variable speed compressor is from $42 \%$ to $100 \%$, respectively from $25 \mathrm{~Hz}$ to $60 \mathrm{~Hz}$. In the actual plant, when the flow rate required exceeds the capability of the master compressor, the slave is switched on at its nominal capacity, while the master modulates at the minimum velocity. Due to these constraints, at the switch between the two compressors the refrigerant flow rate may not coincide with the one required by the instantaneous cooling capacity and the suction pressure could suffer slight variation. This leads to liquid level variations in the receiver which are taken into account in the model by storing the extra amount of refrigerant in a buffer for the following time step neglecting suction pressure oscillations.

The heat recovery in heat exchangers is active whenever the outlet water temperature $\left(t_{w, H R \_o u t}\right)$ is higher than the temperature in the corresponding tank $\left(t_{\text {tank }}\right)$. When the temperature in the tank drops below the minimum value $\left(t_{\text {tank,min }}\right)$, the corresponding HP (Figure1) is activated to bring the set point value $\left(t_{\text {tank,set }}\right)$ back.

$\left\{\begin{array}{l}\text { if } t_{w, H R_{-} \text {out }}>t_{\text {tank }} \vee t_{\text {tank }}<t_{\text {tank,set }} \Rightarrow \mathrm{HR} \text { active } \\ \text { if } t_{\text {tank }}<t_{\text {tank,min }} \Rightarrow \mathrm{HP} \text { active }\end{array}\right.$

The DHW tank set point temperature is set at a temperature of $70{ }^{\circ} \mathrm{C}$ to avoid the growth of legionella. In HR2, the supply temperature varies from $35^{\circ} \mathrm{C}$ to $45^{\circ} \mathrm{C}$. The values of the main design parameters are reported in Table 1.

The plate heat exchangers HR1 and HR2 are modelled individually on the basis of the NTU method where the involved quantities are inferred both from technical data and measurements. The model, despite the limitations of assuming a constant overall heat transfer coefficient and mean values for the fluid specific heat, is able to estimate with good approximation the heat exchanger performance in terms of outlet temperature and heat transfer rate for given inlet temperatures and mass flow rates. The gas cooler is modelled on the basis of a fixed approach which is actually achieved by controlling fan speed. 


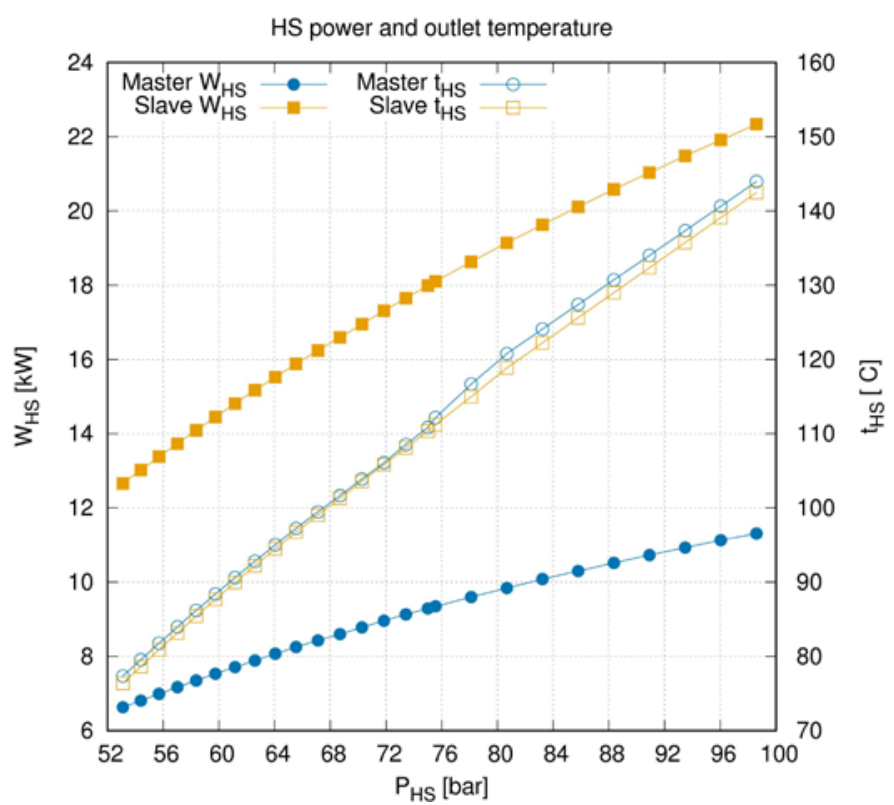

Figure 3: HS compressors nominal power and discharge temperature correlations (suction pressure of $26.5 \mathrm{bar}$, superheating degree of $20 \mathrm{~K})$.

Table 1. Main design parameters for the commercial refrigeration unit

\begin{tabular}{lll}
\hline Parameter & Unit & Value \\
\hline LT evaporating temperature & ${ }^{\circ} \mathrm{C}$ & -35 \\
MT evaporating temperature & ${ }^{\circ} \mathrm{C}$ & -10 \\
Minimum condensing temperature & ${ }^{\circ} \mathrm{C}$ & 6 \\
Liquid receiver pressure $p_{I N T}$ & bar & 35.0 \\
$p_{H S}$ in heat recovery conditions in HR2 & bar & 78 \\
Degree of subcooling at subcritical operation & $\mathrm{K}$ & 3 \\
Gas Cooler/Condenser approach temperature difference & $\mathrm{K}$ & 4 \\
DHW tank setpoint temperature/min temperature & ${ }^{\circ} \mathrm{C}$ & $70 / 55$ \\
HVAC tank setpoint temperature/min temperature (heating use) & ${ }^{\circ} \mathrm{C}$ & $45 / 35$ \\
HVAC tank setpoint temperature/max temperature (AC use) & ${ }^{\circ} \mathrm{C}$ & $7 / 12$ \\
\hline
\end{tabular}

\section{FIELD TESTS AND MODEL VALIDATION}

The data collected by the monitoring system of the refrigerating plant in the supermarket have been thoroughly analyzed in order to prove the values of the setting parameters (Table 1) and infer the values of the intrinsic characteristics of the plant itself necessary to calibrate the model

For instance, the superheating values at the two temperature levels are almost constant in time: $30 \mathrm{~K}$ for LT superheating and $20 \mathrm{~K}$ for MT. Assuming a conservative approach, these values have been introduced in the model as superheating in the suction lines and no useful superheating has been considered in the evaporators. The model has been validated with the monitored data, which were available for the whole year round starting from April 2017. In the following sections, for the sake of brevity, the comparison between the results from 
the simulations and the monitored data is reported for five selected weeks, each one representative of a specific operating condition:

- subcritical week 1 (from the $20^{\text {th }}$ to the $26^{\text {th }}$ of October, 2017);

- subcritical week 2, with heat reclaim (from the $3^{\text {rd }}$ to the $9^{\text {th }}$ of November, 2017);

- transition week 3, with heat reclaim (from the $13^{\text {th }}$ to the $19^{\text {th }}$ of April, 2018);

- transition/transcritical week 4 (from the $11^{\text {th }}$ to the $17^{\text {th }}$ of May, 2018);

- transcritical week 5 (from the $18^{\text {th }}$ to the $24^{\text {th }}$ of May, 2018).

\subsection{CRU model validation}

Validation was first of all performed on the compressor section starting from the known compressor statuses recorded by the monitoring system.

Figure 4 shows the comparison in terms of pressure and temperature, respectively, at the outlet of the HS compressors for three of the selected weeks in different operating conditions. The computed pressure profiles align quite well with the measured data confirming that the compressor correlations and the control rules of the high stage pressure implemented in the model describe accurately the real system in every operating condition. It can be noticed that the gas cooler pressure is raised to $78 \mathrm{bar}$, thus the system is forced to transcritical regime, whenever heat reclaim is activated as imposed by the control rules.

As regards the HS outlet temperature, it is known that heat loss from the compressor and the discharge lines leads to a significant refrigerant temperature drop, which affects the feasibility of heat recovery and was thus investigated. An ambient temperature dependent correction, with an average value of $13 \mathrm{~K}$ temperature drop, was measuered and the corresponding heat loss has been introduced in the model as part of the calibration setting and the corrected profiles are shown in Figure 4. 


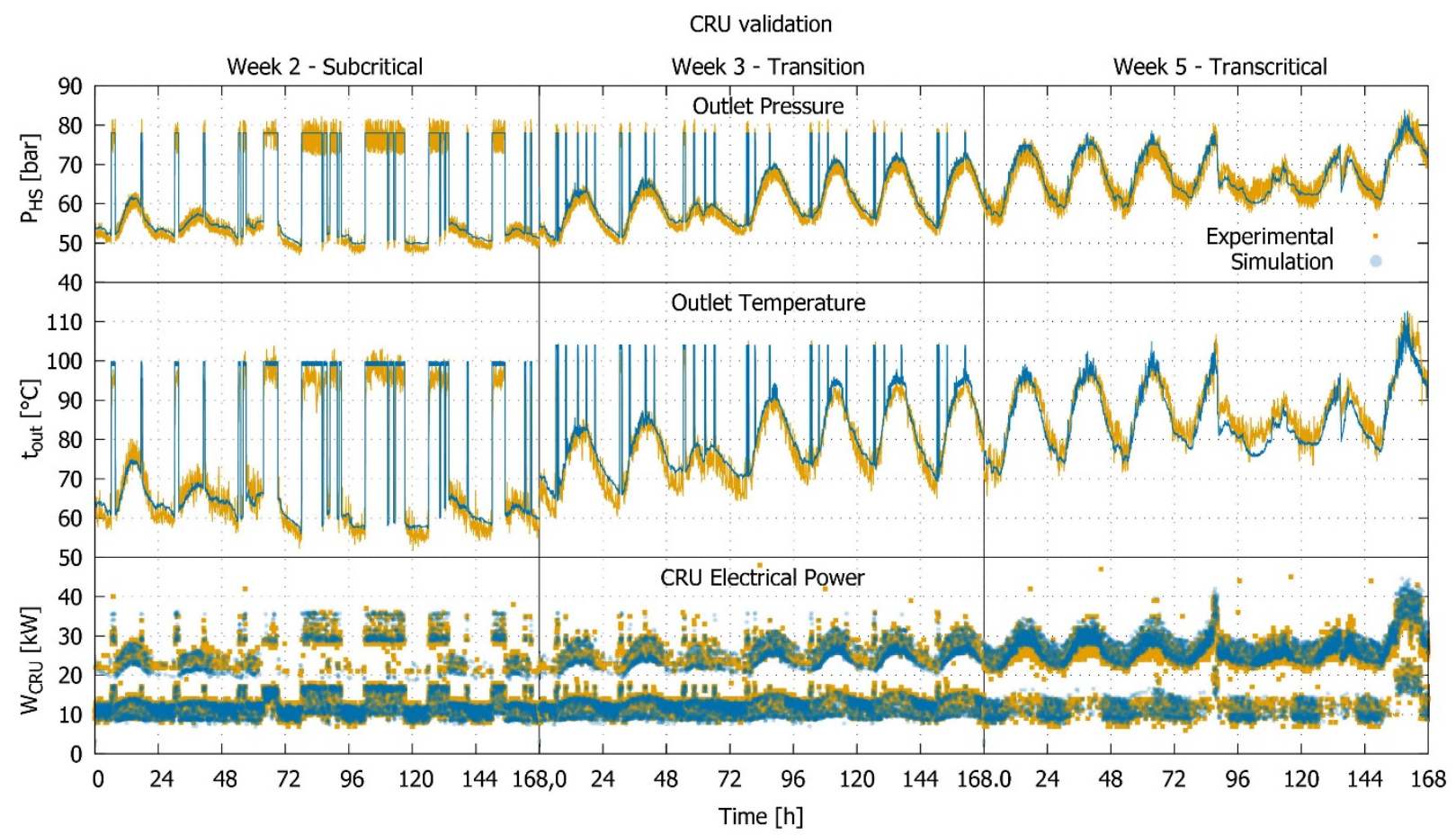

Figure 4: Pressure, temperature at the outlet of HS compressors and CRU electrical power utilization: comparison between monitored data (experimental) and simulated results (simulation) for three of the selected weeks

Furthermore, Figure 4 shows the comparison between the power utilization predicted and measured. In both profiles, two well distinguished patterns are present; the value of the power utilization switches from the lower band to the upper one when the slave HS compressor is activated. This is explained by the fact that in this application the slave compressor size is greater than the inverter controlled one.

The simulated power utilization profile reproduces with good approximation the measured one of the CRU. Indeed, there is a constant difference because the energy meter registers the electrical consumption of the CRU including auxiliaries, which has been found to be on average around $3.2 \mathrm{~kW}$ and is taken into account in the model.

The discrepancy of the simulated weekly electrical energy use values with respect to the measured ones is reported in Table 3 (CRU model) and indicate that the compressor model estimates quite well this fundamental quantity in all operating conditions.

To complete the validation of the CRU model, the weekly cooling energy demand has been estimated based on the actual compressor status values and compared in Table 2 to the monitored values, which has been inferred from the total mass flow of the liquid refrigerant measured by the flow meter at the exit of the receiver. The compressor model predicts the refrigeration load with good approximation, especially in subcritical mode with a slight overestimation when transcritical. If we focused on the liquid flow rate profile instead of thinking in energy terms as we proceeded, it would have been difficult to judge whether the simulated predictions were correct. In fact, figure 5 shows the plot of the measured flow against the simulated one for the subcritical week 1. The simulated data gather around two values: the lower one corresponding to the status when the slave HS 
compressor is switched off and the upper one when it is activated. As the flow meter is placed at the exit of the receiver (Fig. 1), the monitored data is affected by the accumulation of refrigerant in the lines and in the receiver, which partially dampens the big variation at the discharge of HS compressors.

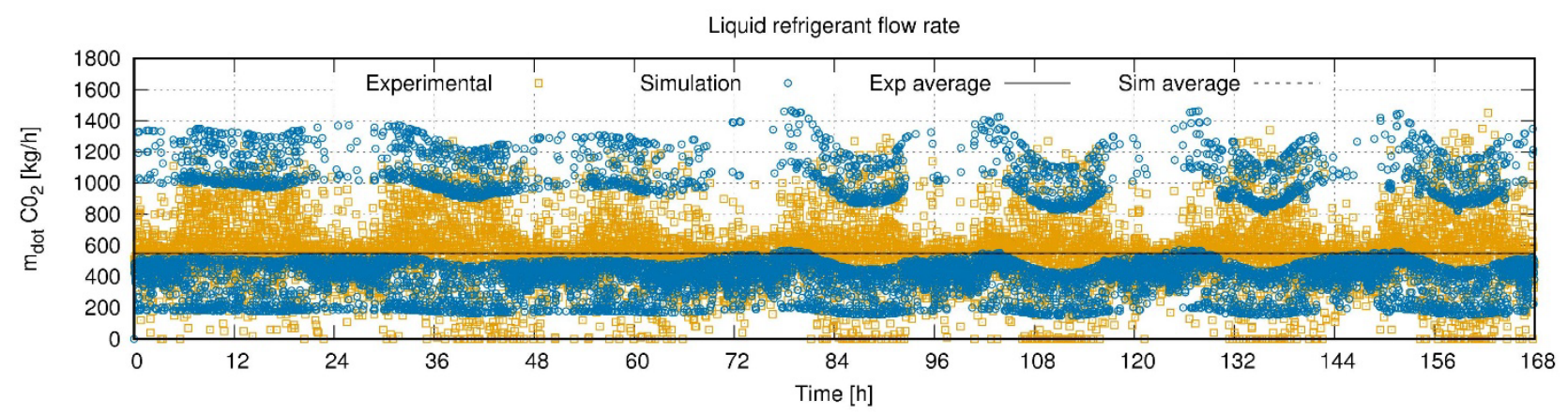

Figure 5: Mass flow rate comparison between monitored data (experimental) and simulated results (simulation) for subcritical week 1

\subsection{RDC model validation}

The second important step in the validation process, after that the compressor section of the CRU model is calibrated, is to validate the prediction of the cooling capacity that is carried out using special in-house types for the refrigerated display cabinets and cold rooms (Polzot, 2017a). A few variables of the monitored data, mainly related to the direct energy consumption of display cabinets and cold rooms, have been used to refine their models. For instance, the signal of defrost operation has been used to correct the defrost frequency and duration, thus influencing the daily profile of the cooling capacity.

As there are no data available to infer the cooling capacity of a single display cabinet nor of a group of them, the only mass flow rate available from the monitoring system, i.e. the one measured at the exit of the liquid receiver, already used to calibrate the CRU, has been once again the reference quantity for the validation of the total cooling capacity. In fact, the comparison between experimental and simulated data is still in terms of total refrigeration energy demand, as already exposed in the previous section.

The inputs of the model are the monitored ambient temperature and relative humidity of the spaces where the RDCs and cold rooms are positioned in the supermarket. In this way it is possible to obtain a more accurate estimation of the total cooling energy required each selected week.

The following Table 2 contains the results for the five selected weeks (RDC model).

Table 2. Comparison between monitored and simulated total cooling capacity for the selected weeks.

Performed with CRU and the RDC model.

\begin{tabular}{ccccc}
\hline Week & Operating conditions & $\begin{array}{c}\text { Monitored total } \\
\text { cooling capacity [MJ] }\end{array}$ & $\begin{array}{c}\text { Error simulated vs } \\
\text { monitored [\%] }\end{array}$ & $\begin{array}{c}\text { RDC model } \\
\text { Error simulated vs } \\
\text { monitored [\%] }\end{array}$ \\
\hline 1 & Subcritical & 21090 & -0.5 & -13.4
\end{tabular}




$\begin{array}{lllll}2 & \text { Subcritical + HR } & 21234 & -0.3 & -12.1 \\ 3 & \text { Transition + HR } & 21774 & 0.1 & -13.8 \\ 4 & \text { Transition/Transcritical } & 22097 & 3.9 & -12.1 \\ 5 & \text { Transcritical } & 22810 & 6.0 & -10.8\end{array}$

The results show that the error in the prediction of total cooling energy demand, and thus of the cooling load, is quite constant throughout the monitoted weeks in different operating conditions, with an underestimation of roughly $12 \%$. This suggests that the error is systematic and that has been adjusted introducing the adequate correction to the rated cooling load of the RDCs, which is more uncertain and subject to error than that of the cold rooms.

\subsection{Refrigeration system model: CRU Electrical Energy utilization and system performance}

The comprehensive model of the whole refrigeration system considers both the prediction of the heat extraction rate from display cabinets and cold rooms, and the performance of the CRU. The compressor statuses are now calculated in the model itself at each time step, once the total cooling load is estimated, together with the refrigerant flow rate at the two evaporating levels.

The comparison in terms of weekly electrical energy utilization between monitored data and simulated ones is reported in Table 3.

Table 3. Comparison between monitored and the overall simulated electrical energy demand for the selected weeks. Performed with CRU and the refrigeration system model (RDC + CRU).

\begin{tabular}{clccc}
\hline Week & Operating conditions & $\begin{array}{c}\text { Monitored Electrical } \\
\text { Energy Demand } \\
{[\mathbf{k W h}]}\end{array}$ & $\begin{array}{c}\text { CRU model } \\
\text { Error simulated vs } \\
\text { monitored [\%] }\end{array}$ & $\begin{array}{c}\text { Refrigeration model } \\
\text { Error simulated vs } \\
\text { monitored [\%] }\end{array}$ \\
\hline 1 & Subcritical & 2535 & -4.6 & -5.8 \\
2 & Subcritical + HR & 2576 & -2.2 & -9.0 \\
3 & Transition + HR & 2980 & -4.3 & -7.0 \\
4 & Transition/Transcritical & 3386 & 2.5 & -4.0 \\
5 & Transcritical & 3821 & 1.1 & -5.4 \\
\hline
\end{tabular}

It can be noticed that the whole model (Refrigeration model) predicts quite well the energy utilization in every operating condition. If compared with the ones calculated with the known compressor statuses (CRU model), it can be observed that the error has increased by approximately $5 \%$ in underestimation. Such difference can be also noticed by the comparison of a weekly profile of the electrical power utilization calculated in the two different ways, figure 6 . 


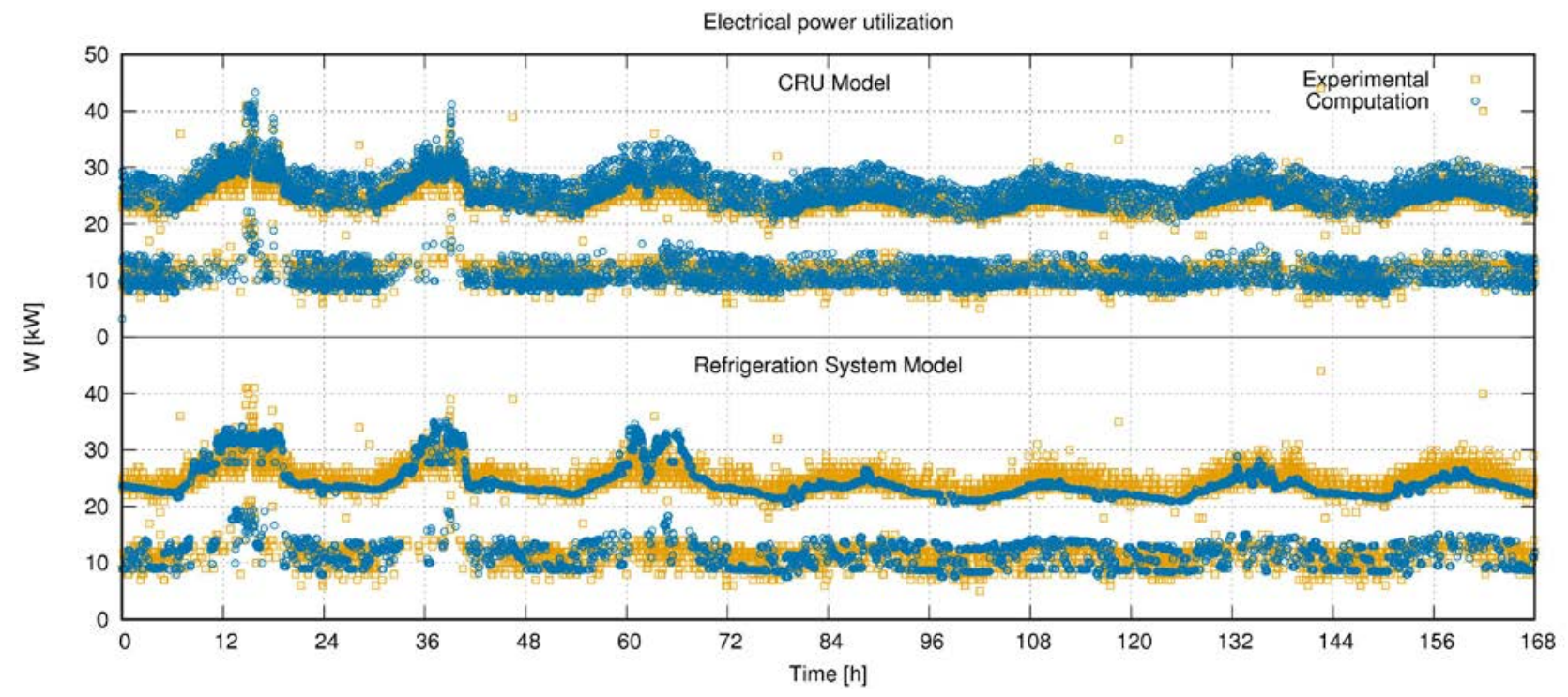

Figure 6: CRU electrical power utilization: comparison between monitored data (experimental) and simulated results

(simulation) for week 4, comparison between single CRU model and the whole refrigeration system model

The difference between the two simulated power profiles in the figure above allows to figure out the behaviour of the control system. In the "Refrigeration system model” profile, the compressor activation status is defined theoretically, to satisfy the cooling load estimated at the display cabinets at each time step. In the CRU model the actual status of the compressors is used as input, and the oscillations introduced by the control system become clearly visible, accounting for a small extra energy consumption. Further constraints are imposed by the operating range of the variable speed compressor, which can lead to incorrect refrigerant flow rate at a single time step. In the actual plant the refrigerant accumulates in the lines and the liquid receiver. In the model, components for refrigerant storage are not considered, and the extra amount of refrigerant is stored as a numerical residual to be used at the following time step. In this way the mass balance is fully satisfied.

In terms of Coefficient of Performance, Figure 7 reports its values obtained from monitoring data and simulations as a function of outdoor temperature when the heat recovery is inactive. Thus, the COP is defined as:

$C O P=\frac{q_{M T+L T}}{W}$

where $W$ is CRU electrical power demand including the auxiliaries (i.e. gas cooler fans) and $q_{M T+L T}$ is the total cooling capacity, which for the simulation data is the output of the 'RDC model' (Figure 2) and for the experimental data is calculated as:

$q_{M T+L T}=\dot{m}_{L T+M T} \cdot \Delta h_{\text {ave }}$

where $\dot{m}_{L T+M T}$ is the total mass flow rate measured at the exit of the liquid receiver and $\Delta h_{\text {ave }}$ is the average value of the enthalpy differences at MT and LT pressures, which differ by less than $1 \%$.

All experimental values are simultaneous and they are estimated at $1 \mathrm{~h}$ time step. They are compared to the simulated ones at the same operating conditions. Of course results are quite scattered, due to the different 
operating conditions which occur at the same outdoor temperature and give place to different values of LT and MT refrigerating loads, as well as sporadic occurrences when the refrigerating load is null. Furthermore, the experimental data are affected by the asynchrony between the compressor status and the refrigerant flow rate measured at the receiver. However, the trend is clear and gives information on the actual operation of a commercial refrigeration $\mathrm{CO}_{2}$ booster system with parallel compression in a mild climate.

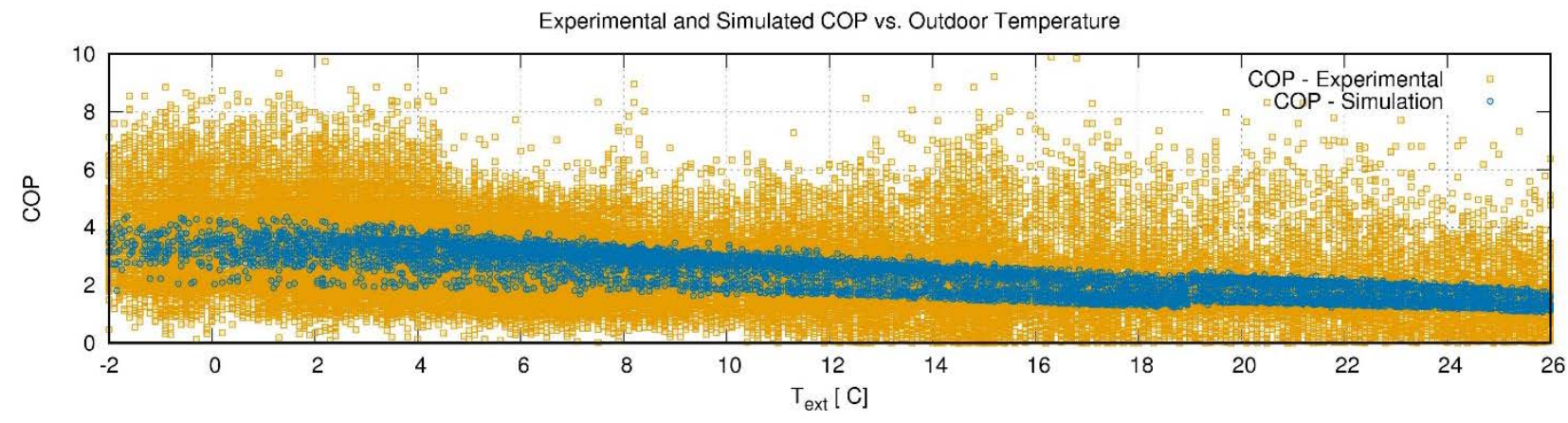

Figure 7: Experimental and simulated values of the Coefficient Of Performance of the refrigerating unit against the outdoor temperature, without any heat recovery

\subsection{Heat recovery exchangers}

The heat exchangers, at both the heat recovery temperature levels, have been analysed. The available data come from energy meters on the water side of the exchangers, which provide the water flow rates along with the inlet and outlet temperatures.

As already mentioned, the heat exchangers are modelled with the NTU method. In order to validate the model, their performance is compared to the simulation for a few selected weeks where heat recovery occurred. In figure 8 the experimental water outlet temperature values are plotted against the computed ones for both the exchangers.
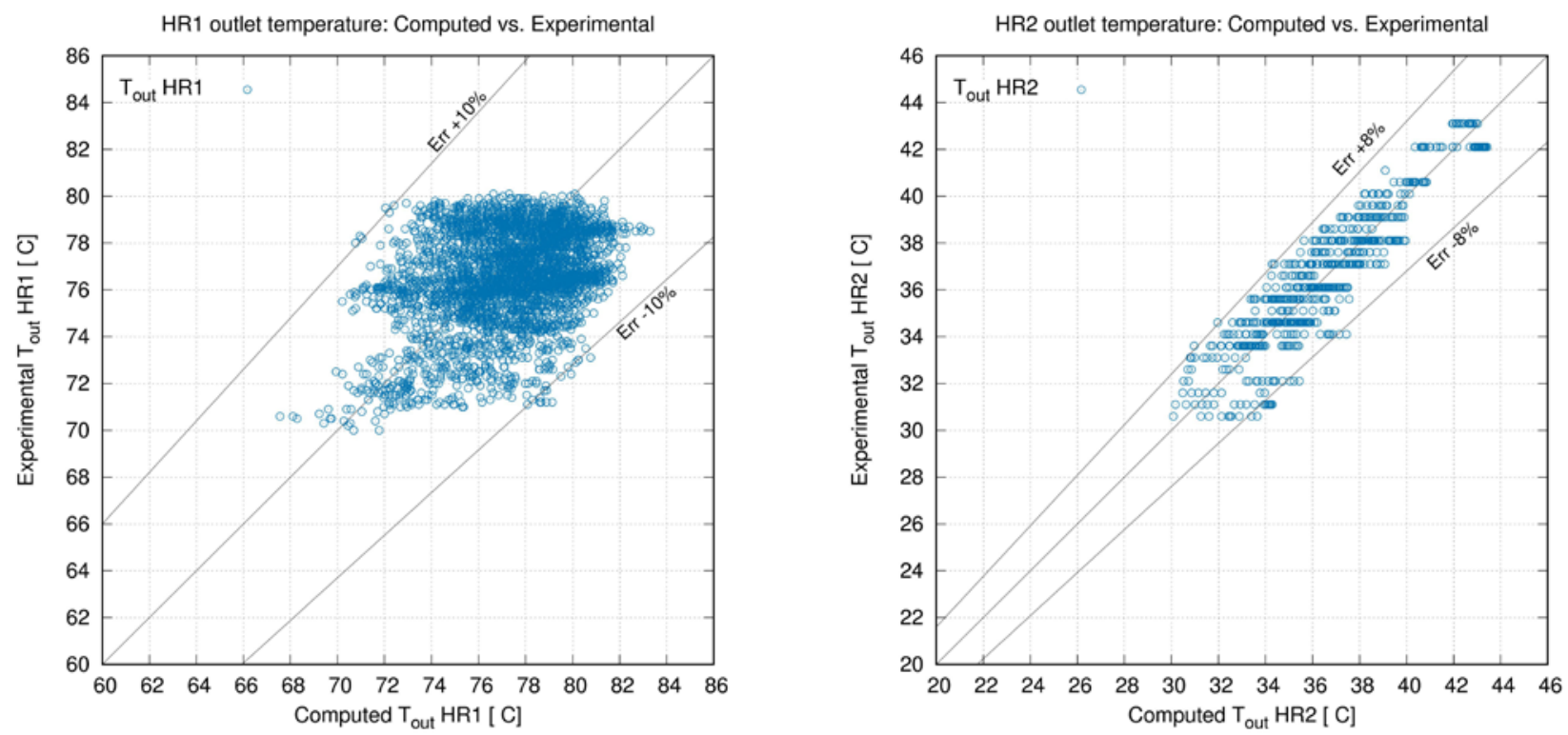
Figure 8: Temperature of secondary fluids at the outet of the heat recovery exchangers HR1 (left) and HR2 (right):

comparison between experimental and computed data.

The model, despite the limitations of assuming a constant overall heat transfer coefficient and mean values for the fluid specific heats, predicts with good approximation, at each temperature level, the value of the water temperature at the exit of the exchangers when heat recovery is required. This ensures an affordable prediction of the potential heat recovery performed with the system under exam.

\section{PERFORMANCE OF THE INTEGRATED SYSTEM}

The validated model can be used to perform rather reliable predictions of the annual electrical energy demand in different scenarios. The main focus is on how to profitably exploit the integration between the refrigeration system and the HVAC units providing both heating or cooling capacity to supply the space heating and AC demands.

The coupling of the refrigerating and DHW/HVAC systems is made through two stratified heat storage tanks (Fig. 1), whose volume is $1 \mathrm{~m}^{3}$ each and set point temperatures are listed in table 1 . Two heat pumps are then connected to the heat storage tanks, to supply the system when the thermal energy at the set point temperature cannot be attained by heat recovery only.

The cases analysed in this work are:

- Case 0 (reference case): the CRU is set to operate only to cover the refrigeration duty of the display cabinets and cold rooms of the supermarket. DHW, AC and heating demands are completely satisfied using dedicated heat pumps and a chiller unit;

- Case 1: when space heating is required the CRU switches to transcritical mode, with a gas cooler pressure of $p_{H S}=78 \mathrm{bar}$, in order to achieve a suitable temperature level at the HS compressors outlet that guarantees to always yield heat at the HR2 exchanger. Heat recovery for DHW at HR1 is performed when freely available, without modifications in the operating conditions of the plant. The same for the cooling capacity for AC, which is provided up to the maximum availability, without changing the operating mode of the CRU;

- Case 2: the same as case 1 , with $p_{H S}=85$ bar when space heating is required, to allow a larger heat recovery at HR2;

- Case 3: as an alternative to case 2, when space heating is required the CRU switches to transcritical mode, with a gas cooler pressure of $p_{H S}=78$ bar. Whenever requested to fulfill the heating demand, an additional aircooled evaporator, placed outdoors, is fed with liquid at the intermediate pressure and used as a supplemental heat source, so that the refrigerant flow rate can be raised, and in turn the available heat at the recovery exchangers. Cooling capacity for the air conditioning system is fully provided.

In cases 1 and 2, the remaining heat needed to fulfil DHW/HVAC demands is integrated with heat pumps. The profiles of the COP of the two heat pumps considered, one for DHW production and the other for the HVAC 
system, are shown in Figure 9 as a function of the outdoor temperature. As regards the AC capacity, the EER of the chiller unit is given by the following expression derived from data (Cecchinato et al., 2010):

$$
E E R=-0.07 t_{\text {outdoor }}+4.74
$$

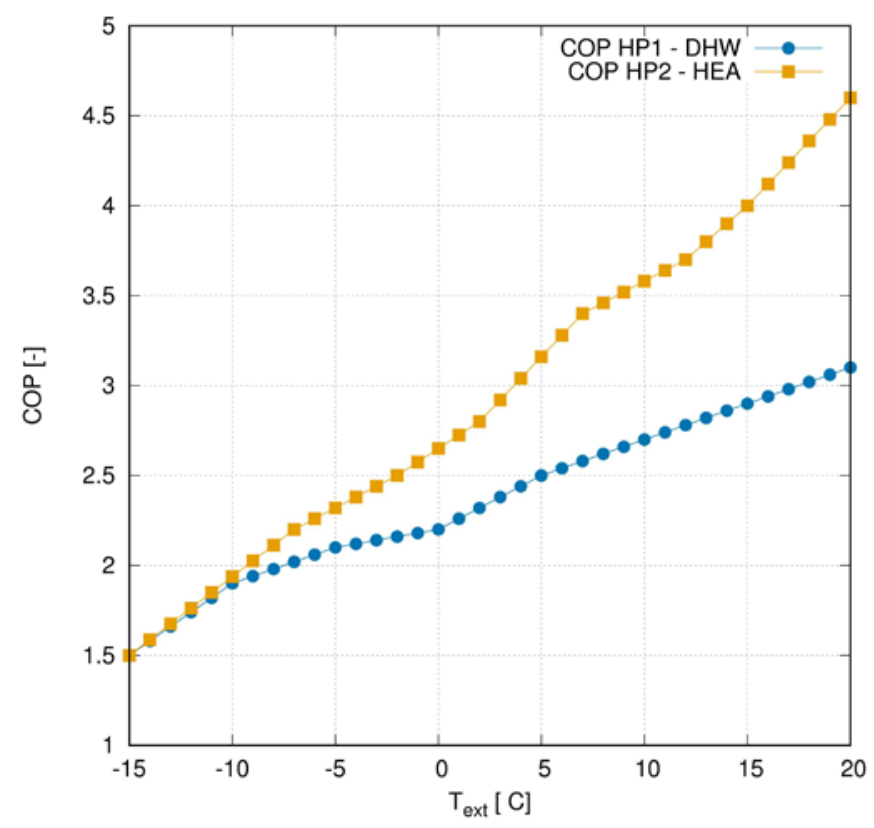

Figure 9: Coefficient of Performance of the heat pumps

The Space Heating and AC demand yearly profiles used in this analysis, obtained from the transient simulation of the thermal behaviour of the building (Dipasquale et al, 2016), are shown in figure 8 together with the profile for DHW, which is based on average experimental data.

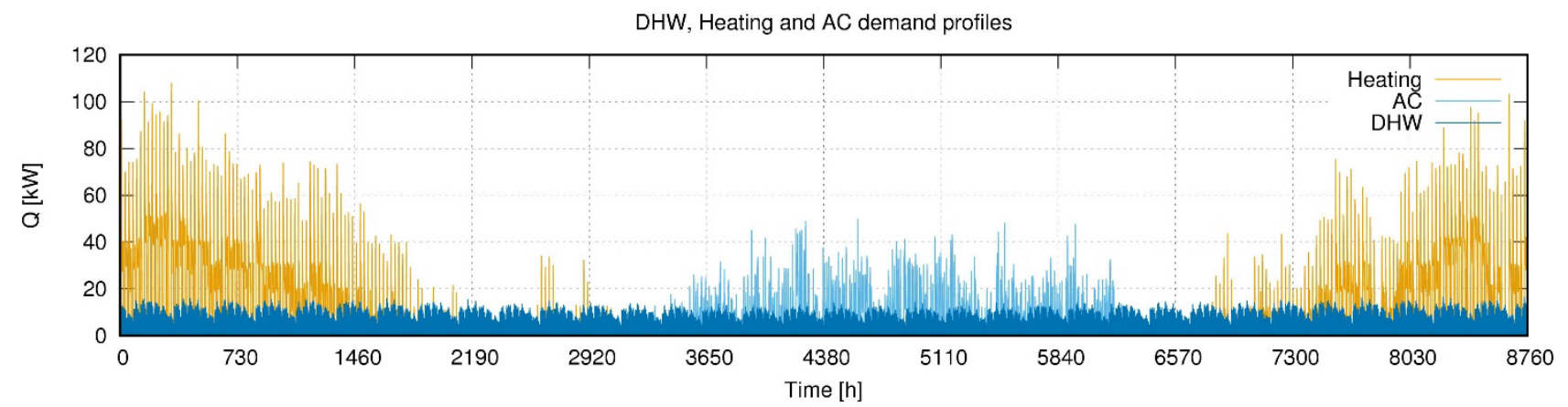

Figure 10: DHW, Heating and AC demand profiles for a whole year.

Figure 10 displays the monthly refrigeration cooling load at LT and MT levels from the simulation of the display cabinets and the cold rooms. The integration between the refrigeration system and the building allows capturing the cooling demand variation over the day and over the year (Figure 10) due to the different indoor set point values, and of the influence of the outdoor conditions when the HVAC is switched off during the closing hours. 


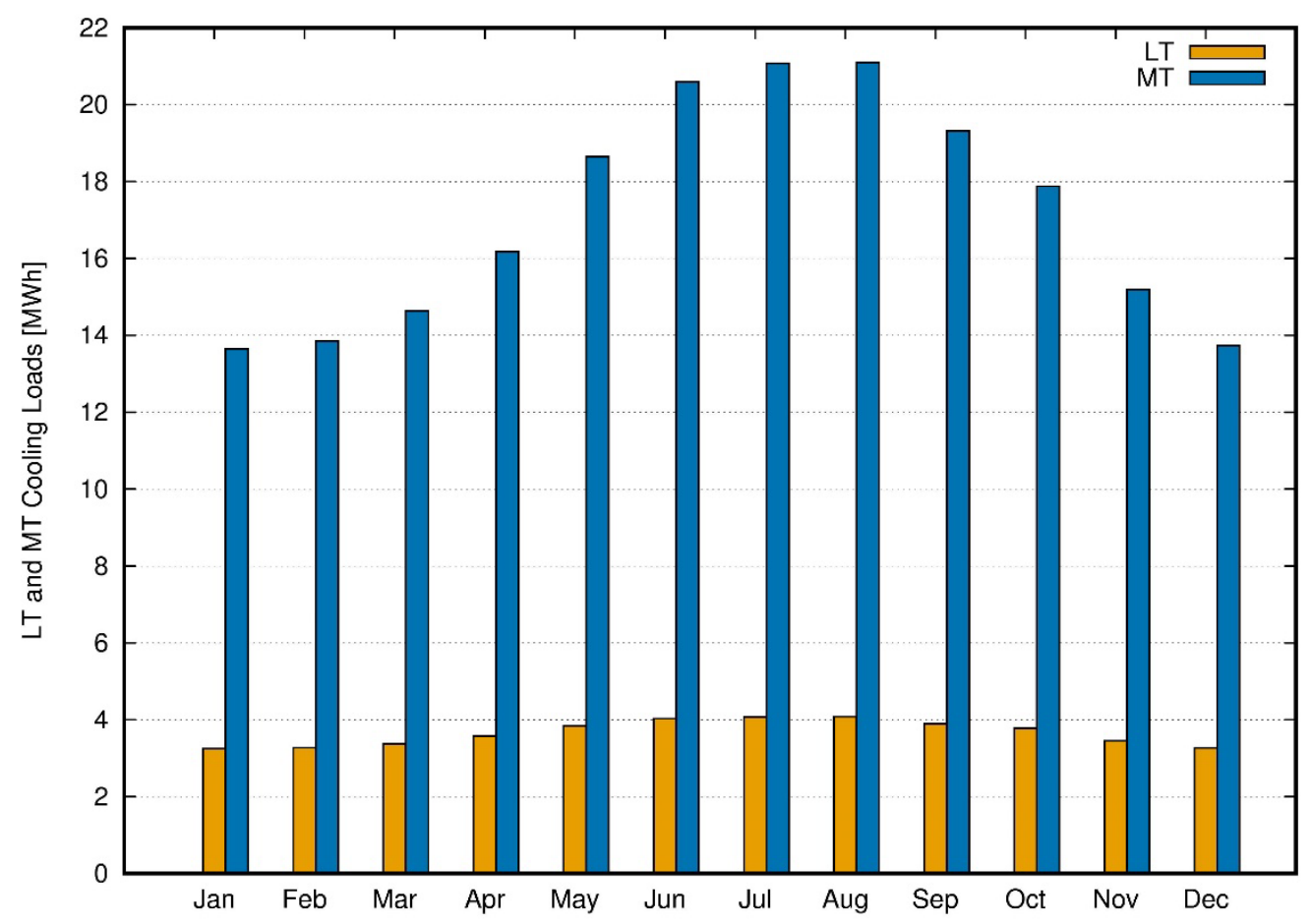

Figure 11: Monthly cooling load on LT and MT evaporators of the refrigerating system.

The electrical energy utilization of the CRU and of the Heat Pumps (HPs) for a whole year, in the analysed cases, is reported in Table 4.

Table 4. Comparison between the annual electrical energy demand of the cases considered.

\begin{tabular}{lcccccc}
\hline \multicolumn{7}{c}{ Annual Electrical Energy Demand [MWh] } \\
\hline CRU & DHW_HP & HEA_HP & AC_HP & Total & $\begin{array}{c}\text { Energy saving } \\
{[\%]}\end{array}$ \\
\hline Case 0 & 125.3 & 12.1 & 18.2 & 6.0 & 161.5 & 0.0 \\
Case 1 & 142.5 & 0.8 & 7.8 & 0.3 & 151.4 & 6.3 \\
Case 2 & 144.5 & 0.8 & 6.5 & 0.3 & 152.0 & 5.9 \\
Case 3 & 149.0 & 0.7 & 0 & 0 & 149.7 & 7.3 \\
\hline
\end{tabular}

It results that the use of CRU coupled with the DHW and HVAC systems leads to savings in the global annual electrical energy utilization, all around $6 \%$ proving that heat recovery is somewhat effective.

On average, in case $1,43 \%$ of space heating remains unsatisfied and thus is covered by the heat pump, while almost all of the DHW and AC demand are fulfilled (the small amount is still covered by the heat pumps). In case 2 , with a higher $p_{H S}$, at the expense of a slightly higher global energy consumption we have that $36 \%$ of space heating that remains unsatisfied, while DHW and AC are again almost completely covered. Case 1 seems to be the more favourable than case 2, showing that a significant undersize of the traditional HVAC heat and cooling power generation units can be achieved with no need to push the gas cooler pressure to really high values. Similarly, increasing the set point temperature for heat recovery in favour of DHW up to $90^{\circ} \mathrm{C}$, in order 
to take advantage of heat storage capacity of the tank, still doesn't lead to the total satisfaction of the DHW demand, or to further significant energy savings.

While case 1 and case 2 are performed running the model of the actual plant, the all-in-one system (case 3), in order to fully fulfil the HVAC demands, needs an additional load evaporator which should be active for $48 \%$ working hours of the heat demanding period and an additional parallel compressor, of the same size of the existing one, that should be active $8.4 \%$ working hours when $\mathrm{AC}$ is required.

It still misses to cover about $6 \%$ of the DHW production mainly concentrated in peak hours in the cold season, which could be easily gained by an additional electrical heater if strictly necessary. In this configuration, the CRU can be identified as a Stand Alone Unit, because there is no need to use other equipment for heating and cooling power generation, thus allowing a major reduction in the investment costs and dimensions of the unit. Some energy saving, around $7 \%$, could even be attained, according to the simulation for this specific climate and for these specific heat pump/chiller performance.

Figure 12 shows the monthly comparison of electrical energy demand of the configurations considered in the analysis.

In case 1 , with respect to case 0 , the electrical energy demand of the CRU grows from $10 \%$ (March) to $41 \%$ (January) in winter to cover HVAC heat recovery needs and it grows from 10\% (June) to 14\% (July) in summer to provide AC power. Every month the total electrical energy demand of the integrated system (Case 1) is always lower than in case 0 . The maximum benefit is yielded in winter, while in the intermediate months (May/October) the electrical energy request is almost the same.

Furthermore, the slight improvement of Case 3 with respect to Case 1 is concentrated in the winter months, showing that such gain is only given by the load evaporator, while the additional parallel compressor only guarantees to cover the rare peaks that occur in the climate considered. 


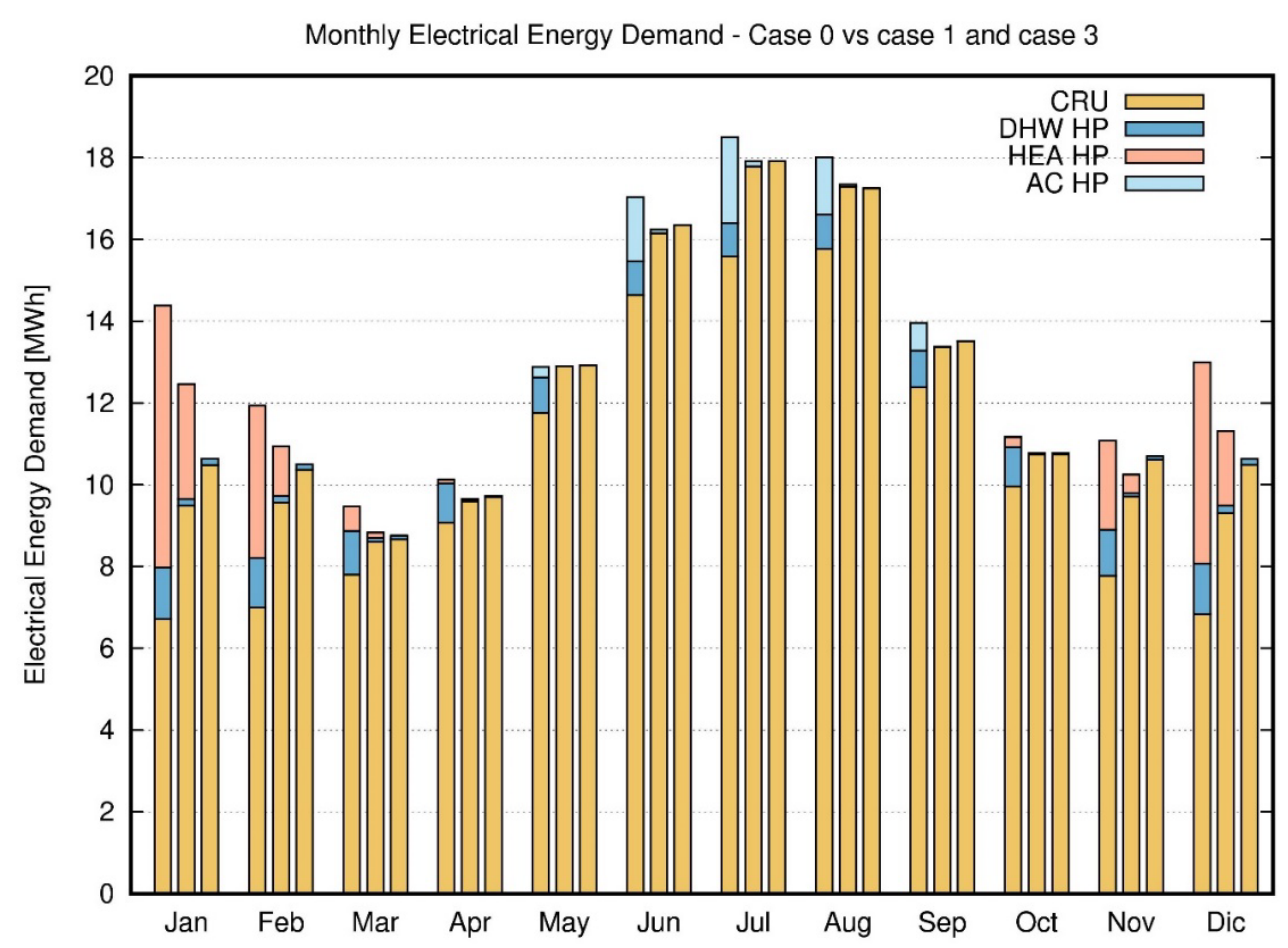

Figure 12: Monthly electrical energy demand for cases 0 (left columns), 1 (central columns) and 3 (right columns).

\section{CONCLUSIONS}

Measurements were performed on a fully instrumented $\mathrm{CO}_{2}$ trans-critical booster system with parallel compression, heat recovery for heating and hot water production purposes and a heat exchanger for air conditioning provision. This system is in operation in a small size supermarket in northern Italy, and measurements allowed to observe its functioning and assess its performance. Such data were used to validate a comprehensive model of the entire refrigeration system of the supermarket, here included the operation of display cabinets and of the refrigerating unit, based on TRNSYS and in-house types for all the components. The model showed to be sufficiently adequate to estimate the refrigerating load of display cabinets and cold rooms, however it revealed that a correct prediction is a complicated task, due to the complex and sometimes random boundary conditions involved. In this case a slight underestimation (around 12\%) of the refrigerating load and thus refrigerant mass flow rate required was experienced. The evaluation of the electrical power use takes into account the operating mode of the compressors, whose control at partial load involves the switch between fixed and variable speed. This is a crucial point, and underlines that simulations performed at constant refrigerating load can be misleading. This statement is confirmed by the scattering encountered in the values of the COP measured on the refrigerating system.

The measurements and further simulations performed on the investigated plant allow to state that, at the climate and operating conditions considered, the system can afford the majority of heating, hot water and air conditioning duties of the supermarket with also a $6 \%$ reduction of the global energy consumption compared to a solution with separate systems.

Simulations with the adoption of an air-cooled evaporator placed outdoors and of an additional parallel compressor revealed the opportunity to fully provide HVAC duties, getting even a slightly lower (7 \%) energy 
consumption. Installation of heat pumps and chillers should then be reconsidered when using a commercial refrigeration $\mathrm{CO}_{2}$ system, in favour of a "standalone" solution advantageous in terms of investment cost, footprint area and refrigerant charge.

Modelling proved to be a powerful tool for the prediction of plant performance at several conditions and when coupled with other systems. A validated model can be effectively employed not only at the design stage for the choice of the preferable configuration, but also as a tool for defining the best control strategies in the view of energy saving, heat recovery and Demand Side Management operation.

\section{ACKNOWLEDGEMENTS}

The research leading to these results has received funding from the MIUR of Italy within the framework of PRIN2015 project «Clean Heating and Cooling Technologies for an Energy Efficient Smart Grid».

\section{REFERENCES}

Bell, I.H, Wronski, J., Quoilin, S., Lemort, V., 2014. Pure and Pseudo-pure Fluid Thermophysical Property Evaluation and the Open-Source Thermophysical Property Library CoolProp. Ind. Eng. Chem. Res. 53(6), 2498-2508.

BITZER, 2017. BITZER v6.7.0 rev1852 - Available at: https://www.bitzer.de/websoftware/ [accessed 07.09.2018].

Cecchinato L., Chiarello M., Corradi M., 2010, A simplified method to evaluate the seasonal energy performance of water chillers. International Journal of Thermal Sciences, 49, 1776-1786.

CommONEnergy 2017. CommONEnergy, Converting EU Shopping Centres Into Beacons Of Energy Efficiency, http://www.commonenergyproject.eu [accessed 20.12.2018].

Cortella G., Lollini R., Noris F., D’Agaro P., Saro O., 2014. CommONEnergy: re-conceptualizing shopping malls from consumerism to energy conservation. In: $3^{\text {rd }}$ IIR International Conference on Sustainability and Cold Chain, London (UK).

Cortella G., D’Agaro P., Coppola M.A., 2018. Simulations and field tests of a $\mathrm{CO}_{2}$ refrigerating plant for commercial refrigeration. In: $13^{\text {th }}$ IIR Gustav Lorentzen Conference on Natural Refrigerants, Valencia (E).

D’Agaro P., Cortella G., Polzot A., 2018. R744 booster integrated system for full heating supply to supermarkets, Int. J. Refrig., https://doi.org/10.1016/j.ijrefrig.2018.09.028

Dipasquale C., Belleri A., Lollini R., Integrative Modelling Environment, Deliverable 4.1. CommONEnergy project.

http://www.commonenergyproject.eu/uploads/deliverable/file/15/WP4_D4_1_20161124_P01_Integrative_M odelling_Environment_FINAL v9.pdf [accessed 20.12.2018] 
Ge, Y.T., Tassou, S.A., 2014. Control optimizations for heat recovery from $\mathrm{CO}_{2}$ refrigeration systems in supermarket, Energ. Convers. Manage., 78, 245-252.

EN12900:2013 Standard: Refrigerant compressors. Rating conditions, tolerances and presentation of manufacturer's performance data

Gullo P., Elmegaard B., Cortella G., 2016. Energy and environmental performance assessment of R744 booster supermarket refrigeration systems operating in warm climates, Int. J. Refrig. 64, 61-79.

Gullo, P., Hafner, A., Cortella, G., 2017. Multi-ejector R744 booster refrigerating plant and air conditioning system integration -a theoretical evaluation of energy benefits for supermarket applications. Int. J. Refrig. 75, 164-176.

Hafner, A., Hemmingsen, A.K., Van de Ven, A., 2014. R744 refrigeration system configurations for supermarkets in warm climates. In: $3^{\text {rd }}$ IIR International Conference on Sustainability and Cold Chain, London (UK)

Hafner A., Banasiak K., 2016a. Full scale supermarket laboratory R744 ejector supported \& AC integrated parallel compression unit. In: $12^{\text {th }}$ IIR Gustav Lorentzen Natural Working Fluids Conference, Edinburgh, UK. Hafner A., Banasiak K ., Herdlitschka T., Fredslund K., Girotto S., Haida M., Smolka J., 2016b. R744 ejector system case: italian supermarket, Spiazzo. In: $12^{\text {th }}$ IIR Gustav Lorentzen Conference Natural Working Fluids, Edinburgh (UK).

Karampour M., Sawalha S., 2014a. Supermarket refrigeration and heat recovery using $\mathrm{CO}_{2}$ as refrigerant. A comprehensive evaluation based on field measurements and modelling. Energimyndigheten, EffsysPlus project, urn:nbn:se:kth:diva-172811 [accessed 20.12.2018].

Karampour M., Sawalha S., 2014b. Performance and control strategies analysis of a $\mathrm{CO}_{2}$ trans-critical booster system. In: $3^{\text {rd }}$ IIR International Conference on Sustainability and Cold Chain, London (UK)

Karampour, M. , Sawalha, S. , 2016a. Integration of heating and air conditioning into a $\mathrm{CO}_{2}$ trans-critical booster system with parallel compression -part I: evaluation of key operating parameters using field measurements. In: $12^{\text {th }}$ IIR Gustav Lorentzen Conference Natural Working Fluids, Edinburgh (UK).

Karampour, M. , Sawalha, S., 2016b. Integration of heating and air conditioning into a $\mathrm{CO}_{2}$ trans-critical booster system with parallel compression -part II: performance analysis based on field measurements. In: $12^{\text {th }}$ IIR Gustav Lorentzen Conference Natural Working Fluids, Edinburgh (UK).

Karampour M., Sawalha S., 2017. Energy efficiency evaluation of integrated $\mathrm{CO}_{2}$ trans-critical system in supermarkets: field measurements and modelling analysis. Int. J. Refrigeration, 82, 470-486.

Karampour M., Sawalha S., 2018. State-of-the-art integrated $\mathrm{CO}_{2}$ refrigeration system for supermarkets: a comparative analysis. Int. J. Refrig. 86, 239-257.

Klein, S.A., Beckman, W.A., Duffie, J.A., 2010. TRNSYS 17, A Transient System Simulation Program, Solar Energy Laboratory, University of Wisconsin, Madison, USA - http://sel.me.wisc.edu/trnsys [accessed 15.05.2018].

Llopis, R., Cabello, R., Sánchez, D., Torrella, E., 2015. Energy improvement of $\mathrm{CO}_{2}$ transcritical refrigeration cycles using dedicated mechanical subcooling. Int. J. Refrig. 55, 129-141. 
Llopis R., Nebot-Andrés L., Cabello R., Sánchez D., Catalán-Gil J., 2016. Experimental evaluation of a $\mathrm{CO}_{2}$ transcritical refrigeration plant with dedicated mechanical subcooling. Int. J. Refrig. 69, 361-368.

Llopis R., Nebot-Andrés L., Sánchez D., Catalán-Gil J., Cabello R., 2018. Subcooling methods for $\mathrm{CO}_{2}$ refrigeration cycles. A Review. International Journal of Refrigeration, 93, 85-107.

Minetto S., Girotto S., Salvatore M., Rossetti A., Marinetti S., 2014. Recent installations of $\mathrm{CO}_{2}$ supermarket refrigeration system for warm climates: Data from the field. In: $3^{\text {rd }}$ IIR International Conference on Sustainability and Cold Chain, London (UK).

Nöding M., Fidorra N., Gräber M., Köhler J., 2016. Operation strategy for heat recovery of transcritical CO2 refrigeration systems with heat storages. In: 29th Int. Conference on Efficiency, Cost, Optimisation, Simulation and Environmental Impact of Energy Systems. Portorož (SLO).

Pardiñas A.A., Hafner A., Banasiak K., 2018. Novel integrated $\mathrm{CO}_{2}$ vapour compression racks for supermarkets. Thermodynamic analysis of possible system configurations and influence of operational conditions. Appl. Therm. Eng. 131, 1008-1025.

Polzot, A., D’Agaro, P., Gullo, P., Cortella, G., 2015. Water storage to improve the efficiency of $\mathrm{CO}_{2}$ commercial refrigeration systems. In: $24^{\text {th }}$ IIR International Congress of Refrigeration; Yokohama, Japan.

Polzot A., D'Agaro P., Gullo P., Cortella G., 2016a. Modelling commercial refrigeration systems coupled with water storage to improve energy efficiency and perform heat recovery. Int. J. Refrig., 69, 313-323.

Polzot A., D'Agaro P., Cortella G., Gullo P., 2016b. Supermarket refrigeration and air conditioning systems integration via a water storage. In: $4^{\text {th }}$ IIR International Conference on Sustainability and the Cold Chain, Auckland (NZ).

Polzot A., 2017a. Energy benefit assessment of various refrigeration systems integrated with HVAC units in shopping malls. PhD Thesis, Università degli Studi di Udine, Italy. https://air.uniud.it/handle/11390/1132161\#.W8htjGgzZaQ [accessed 20.12.2018]

Polzot A., D’Agaro P., Cortella G., 2017b, Energy analysis of a transcritical $\mathrm{CO}_{2}$ supermarket refrigeration system with heat recovery. Energy Proced, 111:648-657, 2017.

Reinholdt, L., Madsen, C., 2010. Heat recovery in retail refrigeration. In: $9^{\text {th }}$ IIR Gustav Lorentzen Conference on Natural Refrigerants, Sydney, (AU).

Sawalha S., 2013. Investigation of heat recovery in $\mathrm{CO}_{2}$ trans-critical solution in supermarket refrigeration, Int. J. Refrig., 36, 145-156. 